\title{
Frações de fibra em aveia e sua aplicação em programas de melhoramento
}

\author{
Cláudia Fernanda Lemons e Silva(1), Sandra Cristina Kothe Milach ${ }^{(2)}$, Sérgio Delmar dos Anjos e Silva ${ }^{(3)}$, \\ Luis Carlos Federizzi( ${ }^{(4)}$, Cândida Raquel Montero ${ }^{(4)}$ e Roberto Serena Fontaneli(5)
}

\begin{abstract}
(1)Universidade Federal de Pelotas, Instituto de Física e Matemática, Dep. de Matemática e Estatística, Caixa Postal 354, CEP 96010-900 Pelotas, RS. E-mail: lemonsc@terra.com.br (2)Pioneer Sementes, Rua Paissandú, no 582, CEP 99010-080 Passo Fundo, RS. E-mail: sandra.milach@pioneer.com (3)Embrapa Clima Temperado, Caixa Postal 403, CEP 96001-970 Pelotas, RS. E-mail: sergio@cpact.embrapa.br (4)Unversidade Federal do Rio Grande do Sul, Fac. de Agronomia, Av. Bento Gonçalves, no 7712, Caixa Postal 15100, CEP 91501-970 Porto Alegre, RS. E-mail: federizi@ufrgs.br, candidaraquel@hotmail.com (5)Universidade de Passo Fundo, Campus I, Caixa Postal 611, CEP $99001-970$ Passo Fundo, RS. E-mail: roberto@upf.br
\end{abstract}

Resumo - O objetivo deste trabalho foi determinar frações de fibra em genótipos de aveia e avaliar o potencial do NIRS, utilizando grãos inteiros e moídos. Grãos descascados, inteiros e moídos, dos genótipos UFRGS 7, UFRGS 14, UFRGS 17 e de 99 linhagens recombinantes $\mathrm{F}_{7}$, de UFRGS 7 x UFRGS 17, foram analisados quanto aos teores de fibras total, solúvel e insolúvel, pelo método enzimático gravimétrico. Amostras de grãos, descascados inteiros e grãos moídos, foram também analisadas pelo NIRS. Os resultados indicaram que a utilização do NIRS, para avaliação do teor de fibras a partir de grãos inteiros, é eficaz e pode ser empregada na seleção desse caráter em aveia.

Termos para indexação: Avena sativa, NIRS, variabilidade genética.

\section{Oat fiber fractions and their application in breeding programs}

\begin{abstract}
The objective of this work was to determine fiber fraction in oat genotypes and to evaluate the use of NIRS with whole and ground groats. Whole oat groats of UFRGS 7, UFRGS 14 and UFRGS 17 and 99 F $_{7}$ recombinant inbred lines from UFRGS 7 x UFRGS 17, were analyzed for total fiber, soluble fiber and insoluble fiber contents, by gravimetric-enzymatic method. Samples of whole and ground groats, were also analyzed by NIRS. The results showed that the NIRS method was efficient to determine fiber content using whole grain, and it is possible to use it for selection in oat.
\end{abstract}

Index terms: Avena sativa, NIRS, genetic variability.

\section{Introdução}

Estudos relacionados ao consumo de fibras e seus efeitos metabólicos e fisiológicos sobre o organismo humano têm sido crescentes nas últimas décadas. Definida como a fração da dieta resistente à digestão pelas enzimas do trato gastrintestinal de mamíferos, a fibra alimentar apresenta-se insolúvel e solúvel em água (White, 2000). A fibra insolúvel se refere à quantidade de lignina, celulose e algumas hemiceluloses insolúveis, ao passo que a fibra solúvel se refere às substâncias pécticas e hemiceluloses solúveis, predominantemente (Lee \& Prosky, 1995; White, 2000).

Ingredientes ricos em fibra têm sido pesquisados para melhorar a qualidade nutricional e funcional das dietas. Um desses ingredientes é a aveia cuja fibra se encontra principalmente em tecidos externos dos grãos, tendo função estrutural e de proteção. Esses tecidos contêm mais de $70 \%$ do total da fibra alimentar, enquanto o endosperma apresenta quantidades relativamente pequenas (Gutkoski \& Trombetta, 1998). As beta-glicanas solúveis, por constituírem aproximadamente $85 \%$ da fração solúvel da aveia, são intensamente estudadas neste cereal (White, 2000). O desenvolvimento de genótipos com maior teor de fibras solúveis é um alvo importante a ser alcançado pelos melhoristas, no entanto são necessários métodos de avaliação que possam facilitar a seleção dessas características.

De acordo com a Resolução no 40, de 21 de março de 2001, da Agência Nacional de Vigilância Sanitária (Brasil, 2001), a informação nutricional de produtos industrializados como flocos e cereais matinais, entre outros, é obrigatória no rótulo de produtos industrializados e deve incluir o teor de fibra alimentar presente. Este é 
outro motivo que justifica o desenvolvimento de metodologias que facilitem a análise desse componente de qualidade.

No Brasil, um dos métodos utilizados na determinação da fibra alimentar é o enzimático-gravimétrico, reconhecido pela AOAC (Association of Official Analytical Chemists, 1995). Contudo, a implementação desta análise é complexa, uma vez que sua aplicação consome muito tempo, é de custo elevado, devido à utilização de enzimas, além de exigir mão-de-obra.

A técnica de espectroscopia de reflectância no infravermelho próximo (NIRS, Near-Infrared Reflectance Spectroscopy) vem sendo utilizada para medir constituintes de diferentes vegetais de forma rápida e precisa. No passado, o NIRS foi usado com sucesso na determinação de proteína, gordura e fibra de vários produtos e espécies vegetais (Kays et al., 1996). Embora o NIRS tenha amplitude para detectar espécies e constituintes químicos, pouco tem sido estudado quanto à utilização dessa técnica para determinação de fibra alimentar, pela dificuldade na obtenção de dados físico-químicos, fundamentais para o desenvolvimento de curvas de predição. Esta dificuldade tem sido descrita também por outros autores (Hicks et al., 2002).

O objetivo deste trabalho foi determinar as frações de fibras em linhas recombinantes de uma população de aveia, e avaliar o potencial do NIRS para determinação de fibras, utilizando grãos inteiros e moídos.

\section{Material e Métodos}

Amostras de grãos de 99 linhagens $F_{7}$, oriundas do cruzamento de UFRGS 7 e UFRGS 17, bem como de repetições dos genitores, cultivadas no inverno de 2001, na Estação Experimental, da Universidade Federal do Rio Grande do Sul (UFRGS), em Eldorado do Sul, foram descascadas e escolhidas manualmente, eliminando-se os grãos quebrados e parcialmente descascados. Essas amostras foram divididas em duas partes, sendo uma delas moída a granulometria de 0,35-0,5 mm, em moinho Tecator, modelo Knifetec 1095, por 50 segundos. Da fração moída, uma porção foi usada para a análise do teor de fibra alimentar pelo método enzimáticogravimétrico e serviu como referência para calibração. Outra porção moída foi usada para análise de fibra alimentar pelo NIRS. Parte da amostra de grãos descascados e não moídos (inteiros) também foi utilizada para análise no NIRS. Assim, duas curvas de calibração foram obtidas nesse equipamento, uma com dados de grãos inteiros e outra de grãos moídos. Para a equação de calibração, foi utilizada a análise dos componentes principais (PLS), e os outliers foram descartados.

Na determinação de fibra total, solúvel e insolúvel, foi utilizado o método enzimático-gravimétrico descrito por Prosky et al. (1992). A base de determinação dessas frações consiste em submeter a amostra moída $(0,5-0,35 \mathrm{~mm})$ à digestão enzimática com amilase, protease e amiloglicosidase. As enzimas utilizadas foram cedidas pela Novozymes do Brasil Ltda. Depois do tratamento enzimático, o resíduo resultante foi filtrado imediatamente, para obtenção de fibra insolúvel, ou sofreu precipitação etanólica, para determinação de fibra total. A fibra solúvel é obtida pela diferença das duas frações. Em cada resíduo, foram realizadas determinações de proteína e cinzas, para a obtenção dos valores corrigidos de cada fração de fibra avaliada. As amostras foram analisadas em duplicata e, além disso, também foram conduzidas provas em branco.

Em béquer de $400 \mathrm{~mL}, 1 \mathrm{~g}$ da amostra moída foi pesado e anotada a pesagem, em quatro repetições. Em cada béquer, foram adicionados $50 \mathrm{~mL}$ de tampão fosfato $\mathrm{pH}$ 6,0 e $100 \mu \mathrm{L}$ de alfa-amilase termoestável (Termamyl 120-L). Os recipientes foram tampados com papel-alumínio e levados a banho-maria a $100^{\circ} \mathrm{C}$ com agitação, por meia hora. Após resfriamento e correção do $\mathrm{pH}$ para 7,5, as amostras foram incubadas a $60^{\circ} \mathrm{C}$, com protease (alcalase), por 30 minutos, sob agitação. Por último, o pH das amostras foi corrigido para 4,5, adicionado $300 \mu \mathrm{L}$ da enzima amiloglicosidase (AMG 200L) e levadas a banho-maria, sob agitação, por 30 minutos. Depois desse período, duas das amostras foram usadas para fibra total (FT) e duas para fibra insolúvel (FI).

As duas amostras para determinação de fibra total foram tratadas com $280 \mathrm{~mL}$ de etanol 95\%, previamente aquecido a $60^{\circ} \mathrm{C}$, por uma hora, para precipitar a fibra solúvel. Decorrido o tempo, o material foi filtrado em cadinho contendo $1 \mathrm{~g}$ de lã de vidro, pesado anteriormente. O resíduo presente no cadinho filtrante foi lavado com etanol a 78\% (três vezes), etanol a 95\% (duas vezes) e acetona (duas vezes).

Na determinação da fibra insolúvel, depois da incubação com a última enzima (AMG), as amostras foram imediatamente filtradas e lavadas com $60 \mathrm{~mL}$ de água destilada, etanol a $95 \%$ e por último com acetona. Depois da lavagem, todas as repetições foram deixadas por uma noite na estufa a $105^{\circ} \mathrm{C}$, e pesadas no dia seguinte. 
Imediatamente depois do tratamento enzimático, o resíduo resultante foi filtrado, para obtenção de fibra insolúvel, ou sofreu precipitação etanólica, para determinação de fibra total. Em seguida as amostras foram filtradas e lavadas com álcool e acetona. Depois da lavagem todas as repetições foram deixadas por uma noite na estufa a $105^{\circ} \mathrm{C}$, e pesadas no dia seguinte.

Das duplicatas, uma foi utilizada para determinação do teor de proteína pelo método micro Kjeldahl (Tedesco et al., 1985) e a outra para determinação do teor de cinzas (mufla a $525^{\circ} \mathrm{C}$ por cinco horas). Essas determinações foram utilizadas para corrigir os valores de cada fração de fibra avaliada. A fibra solúvel foi obtida pela diferença das duas frações. O peso seco foi calculado pela diferença da amostra úmida e amostra seca a $105^{\circ} \mathrm{C}$ por 24 horas. A porcentagem de fibra total (FT) presente na amostra (expressa em porcentagem do peso seco) foi obtida por meio da fórmula: FT = (resíduo de digestão - cinzas - proteína - branco)/ peso seco da amostra, em que: resíduo de digestão é o peso médio das duplicatas, e o branco é a FT determinada na amostra em branco.

Para determinação das frações de fibra alimentar por meio do NIRS, foram utilizados aproximadamente $5 \mathrm{~g}$ de grãos inteiros descascados e de grãos moídos das mesmas constituições genéticas. As leituras dos espectros das amostras foram obtidas em aparelho da NIRSystems, modelo 5000, digitalizadas, gravadas na forma de $\log (1 / \mathrm{R})$ e processadas pelo programa New Infrasoft International software. Na calibração dos dados, foi utilizada uma seleção de amostras obtidas por meio do algoritmo select sample. A estatística de calibração incluiu erro-padrão de calibração (EPC) e coeficiente de determinação $\left(\mathrm{R}^{2}\right)$. Para validação, foi utilizado o erro-padrão de validação cruzada (EPVC) e o coeficiente de determinação $\left(\mathrm{R}^{2}\right)$.

\section{Resultados e Discussão}

Os valores de média, desvio-padrão, máximos e mínimos, obtidos na comparação dos métodos de análise pelo método enzimático-gravimétrico e os preditos pelo NIRS para fibra total, insolúvel e solúvel estão descritos na Tabela 1. As correlações entre os métodos de avaliação indicam que os resultados obtidos por meio do NIRS podem ser utilizados com boa precisão.

A variabilidade no teor de fibra solúvel foi maior do que em outras frações. Essa variabilidade pode ser explorada na seleção, porém, quanto à fibra solúvel, os resultados da calibração foram inferiores aos obtidos na fibra total e insolúvel. Tal fato pode ser devido à forma indireta para determinação da fibra solúvel, obtida pela diferença entre as frações total e insolúvel calculados pelo método convencional.

O conteúdo de fibra insolúvel e solúvel e suas composições em genótipos de aveia apresentam variabilidade que pode ser explorada no desenvolvimento de genótipos com teor e composição de fibra desejada, de acordo com sua finalidade (Manthey et al., 1999). Teores de 9,28 a 13,86\%, para fibra total, 4,87 a 10,07\%, para fibra insolúvel e 2,26 a 7,25\%, para fibra solúvel, foram encontrados em genótipos brasileiros de aveia (Gutkoski \& Trombetta, 1998). Dessa forma, a faixa de variação dos valores para essas características, neste trabalho, está de acordo com a observada em genótipos de aveia cultivados em ambientes do Sul do Brasil, indicando a possibilidade de seleção para obtenção de genótipos superiores quanto aos teores de fibras.

O erro-padrão de validação cruzada alcançado quanto à fibra total foi $0,27 \%$, nos grãos moídos, e $0,15 \%$ nos grãos inteiros. Quanto à fibra insolúvel, o erro-padrão de validação cruzada obtido foi de $0,33 \%$ para grãos

Tabela 1. Número de amostras (N), média das amostras, desvio-padrão (DP), mínimo e máximo, e correlação (r) entre os valores determinados pelo método enzimático-gravimétrico e os preditos pelo NIRS usando grãos inteiros, para fibras total, insolúvel e solúvel da população UFRGS 7 x UFRGS 17 e seus progenitores.

\begin{tabular}{|c|c|c|c|c|c|c|}
\hline Método & $\mathrm{N}$ & Média & DP & Mínimo & Máximo & $\mathrm{r}(\%)$ \\
\hline \multicolumn{7}{|c|}{ Fibra total } \\
\hline Enzimático -gravimétrico & 72 & 8,74 & 1,5582 & 7,45 & 10,25 & \multirow{2}{*}{98,75} \\
\hline NIRS & 72 & 8,74 & 1,5566 & 7,83 & 10,33 & \\
\hline \multicolumn{7}{|c|}{ Fibra insolúvel } \\
\hline Enzimático -gravimétrico & 69 & 6,15 & 1,1627 & 5,21 & 7,20 & \multirow{2}{*}{95,09} \\
\hline NIRS & 69 & 6,18 & 1,1243 & 5,28 & 7,03 & \\
\hline \multicolumn{7}{|c|}{ Fibra solúvel } \\
\hline Enzimático-gravimétrico & 68 & 2,58 & 0,6667 & 1,60 & 4,76 & \multirow{2}{*}{69,94} \\
\hline NIRS & 68 & 2,55 & 0,6079 & 1,44 & 4,42 & \\
\hline
\end{tabular}


moídos e de $0,25 \%$ para grãos inteiros (Tabela 2). Tanto em fibra total quanto em fibra insolúvel, o erro-padrão de validação cruzada (EPVC) foi menor quando utilizados grãos inteiros, o que indica que a calibração de fibras, com essa forma física de amostra, pode ser realizada satisfatoriamente. Wu \& Shi (2004) também alcançaram boas predições quanto ao teor de amilose, usando grãos inteiros de arroz, o que indica que o NIRS pode ser usado na determinação de características de qualidade química, como teores de fibras, sem necessidade de moagem das amostras.

Poucos estudos têm sido realizados a fim de determinar equações de calibração de fibras de alimentos usando NIRS. Segundo Borges et al. (2001), as equações de calibrações para fibras normalmente não são tão boas quanto as obtidas em outros constituintes, como, por exemplo, proteína bruta. Este fato pode ser devido às imprecisões dos métodos de análises de fibras, e segundo Cervantes-Martinez et al. (2002), boas curvas de calibração para fibras requerem maior número de amostras em relação ao necessário para proteína e óleo.

As frações de fibras nos grãos são muito pequenas, 0 que contribui para que erros maiores sejam verificados nas determinações laboratoriais. Além disso, a fração solúvel da fibra sofre influências ambientais, logo o conhecimento dessa interação pode ser fundamental ao permitir que se minimize essas interações em campo e, assim, melhorar a calibração para fibra solúvel.

Resultados de baixas predições para frações de gorduras, usando linhagens e híbridos de sorgo, foram encontrados por Hicks et al. (2002), e atribuídos à complexidade das características estudadas e à baixa variabilidade encontrada quanto a essas características. Estes fatores devem ser considerados em relação a fibras e suas frações e podem ser válidos também para os resultados deste trabalho.

Tabela 2. Número de amostras (N), média das amostras, erropadrão de calibração (EPC), coeficiente de determinação $\left(\mathrm{R}^{2}\right)$, erro-padrão de validação cruzada (EPVC) e coeficiente de determinação de validação $\left(\mathrm{R}^{2} \mathrm{~V}\right)$ para fibra alimentar em grãos de aveia moídos e inteiros.

\begin{tabular}{llllllll}
\hline Grãos & Variáveis & $\mathrm{N}$ & Média & $\mathrm{EPC}$ & $\mathrm{R}^{2}$ & EPVC & $\mathrm{R}^{2} \mathrm{~V}$ \\
\hline Moídos & & & & & & & \\
& Fibra total & 85 & 9,11 & 0,26 & 0,61 & 0,27 & 0,66 \\
& Fibra insolúvel & 82 & 6,29 & 0,32 & 0,42 & 0,33 & 0,54 \\
\hline Inteiros & & & & & & & \\
& Fibra total & 85 & 8,98 & 0,14 & 0,82 & 0,15 & 0,92 \\
& Fibra insolúvel & 82 & 6,33 & 0,25 & 0,57 & 0,25 & 0,71 \\
\hline
\end{tabular}

As correlações entre os resultados dos teores de fibra total e de fibra insolúvel, determinados por ambos os métodos, para grãos moídos e inteiros, estão representadas na Figura 1. Os coeficientes de correlação alcançados demonstram a eficiência do NIRS para predição das frações de fibra alimentar (Tabela 1). Além disso, na Figura 1 verifica-se ausência de restrições quanto à forma física da amostra utilizada (grãos moídos x grãos inteiros), ou seja, a moagem dos grãos pode ser dispensada, o que aumenta a rapidez de estimativa dos valores de fibra alimentar em grãos de aveia pelo NIRS.

A utilização de grãos inteiros, ao invés de moídos, poderia ser discutida, pois a reflectância da luz sobre a superfície da amostra poderia não refletir a composição do interior dos grãos. Além disso, o tamanho e a forma dos grãos podem influenciar a predição dos resultados. Considerando-se tais fatores, recomenda-se a moagem fina das amostras para a análise no NIRS que utiliza o sensor de reflectância (Borges et al., 2001). Os resultados, entretanto, contrariam essas afirmativas, pois a calibração com grãos inteiros apresentou maiores correlações do que as com grãos moídos (Tabela 2; Figura 1). Uma explicação pode ser a de que a utilização de aparelhos de varredura, com sistema de retículas holográficas, como o aparelho NIRS, não tem as mesmas limitações dos aparelhos de NIRS que usam, como detectores, o sulfito de chumbo, e não consegue medir a luz que incide sobre grãos mais espessos.

A utilização de grãos intactos é mais eficaz para o melhoramento genético, pois torna mais ágil a seleção, permitindo que seja realizada mesmo quando não se dispõe de grande quantidade de grãos, principalmente quando se deseja selecionar em gerações mais precoces. Wu \& Shi (2004) utilizaram grãos individuais de linhas $\mathrm{F}_{2}$ e variedades do grupo indica e japonica, sugerindo que a seleção precoce, quando se dispõe de amostras menores, pode ser feita com o NIRS.

Genótipos com elevados teores de fibra solúvel podem ser utilizados para controle de colesterol, enquanto genótipos com maiores teores de fibra insolúvel poderiam ser destinados à redução de energia em dietas e para a prevenção de constipação. Quando o objetivo do melhoramento é a alimentação animal, deve-se considerar que as frações de fibra podem alterar o ganho de peso e a conversão alimentar de aves (Silva, 2002) e, nesse caso, as proporções das frações solúvel e insolúvel 
da fibra presente na dieta é que afetarão o desempenho animal. Portanto, a partir do conhecimento das frações da fibra nos diferentes genótipos, estes podem ser usados de forma direcionada para finalidades específicas, tanto na alimentação humana quanto animal. Sendo assim, o desenvolvimento de genótipos, com teores diferenciados de fibras, pode se constituir um novo desafio para o melhoramento genético de aveia e um avanço no melhoramento da qualidade deste cereal.
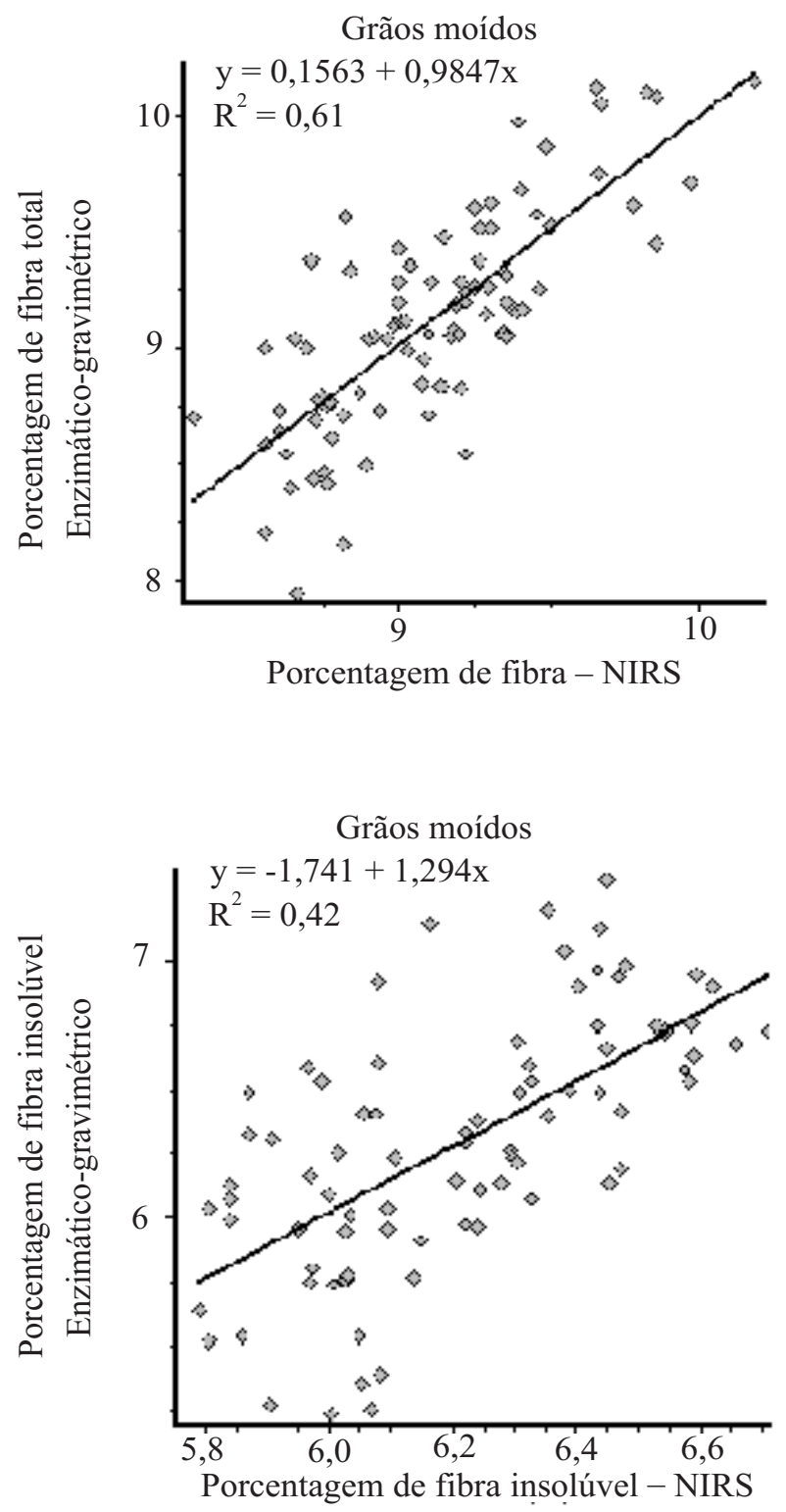

Métodos mais rápidos e eficientes para viabilizar a implementação da seleção dessa característica são fundamentais para o melhoramento de fibras se tornar uma realidade. A utilização de grãos inteiros, sem necessidade de moagem prévia, é uma importante contribuição deste trabalho, que possibilita implementar esta técnica com mais rapidez e menor custo. Os resultados obtidos neste trabalho mostram a grande aplicação do NIRS na determinação de fibras em genótipos brasileiros de aveia.

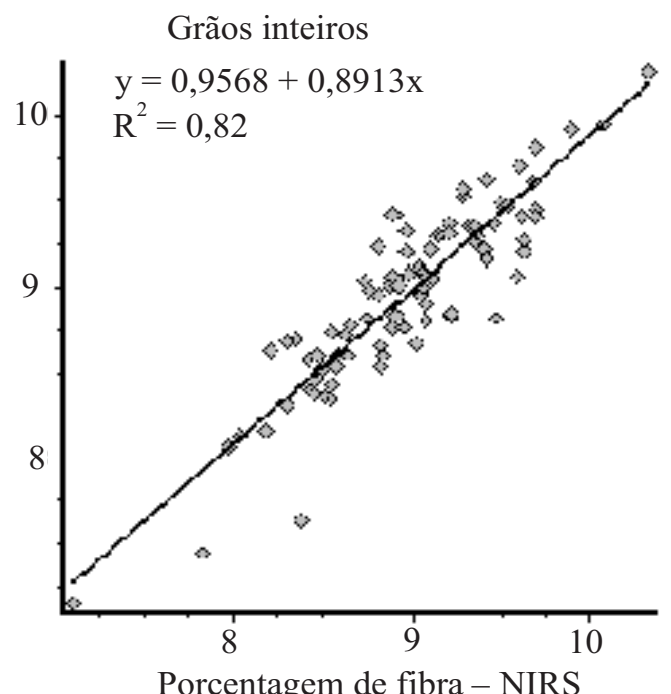

Porcentagem de fibra - NIRS

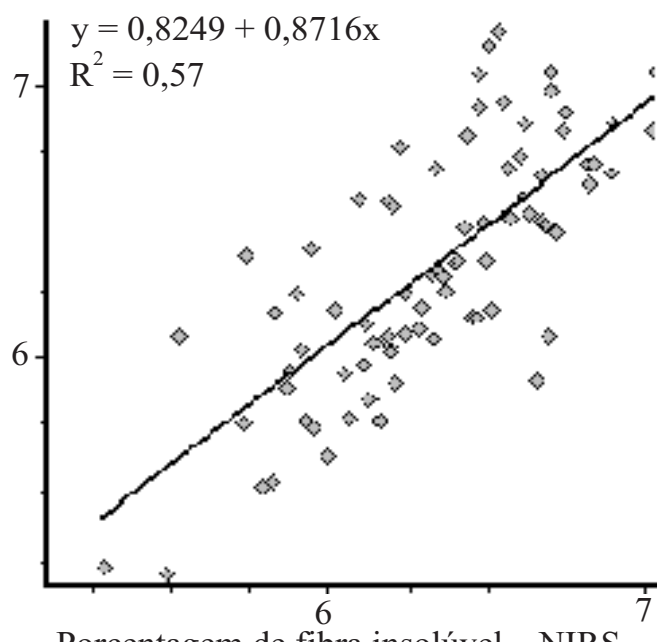

Porcentagem de fibra insolúvel - NIRS

Figura 1. Porcentagem de fibras total e insolúvel (\%), determinadas pelo método enzimático-gravimétrico e predita pelo NIRS, utilizando amostras de dados de grãos moídos e de grãos inteiros. 


\section{Conclusões}

1. Existe variabilidade quanto ao caráter fibra alimentar, que pode ser explorada em programas de melhoramento genético, entre cultivares brasileiras de aveia e suas progênies $\mathrm{F}_{7}$.

2. A utilização do NIRS para predição do teor de fibras em aveia a partir de grãos inteiros é eficaz, podendo ser empregada com êxito na seleção do caráter.

\section{Referências}

ASSOCIATION OF OFFICIAL ANALYTICAL CHEMISTS Official methods of analysis of Association of Official Analytical Chemists International. $16^{\text {th }}$ ed. Arlington, 1995. 2v.

BORGES, F.M.O.; FERREIRA, W.M.; SALIBA, E.O.S Espectroscopia de reflectância no infravermelho próximo NIRS princípios e aplicações na nutrição e alimentação animal. Revista do Conselho Federal de Medicina Veterinária, v.7, p.43-58, 2001.

BRASIL. Ministério da Saúde. Agência Nacional de Vigilância Sanitária. RDC nํㅜ 40, de 21 de março de 2001. Regulamento técnico para rotulagem nutricional obrigatória de alimentos e bebidas embaladas. Diário Oficial da União, n.57-E, 22 mar. 2001. p.22-25.

CERVANTES-MARTINEZ, C.T.; FREY, K.J.; WHITE, D.M.;WESENBERG, D.M.; HOLLAND, J.B. Correlated responses to selection for greater $\beta$-glucan content in two oat populations. Crop Science, v.42, p.730-738, 2002.

GUTKOSKI, L.C.; TROMBETTA, C. Determinação de fibra alimentar insolúvel, solúvel e total em cariopses de aveia (Avena sativa L.). In: REUNIÃO DA COMISSÃO SUL-BRASILEIRA DE PESQUISA DE AVEIA, 18., Londrina, 1998. Resultados experimentais. Londrina: Iapar, 1998. p.63-67.
HICKS, C.; TUINSTRA, M.R.; PEDERSEN, J.F.; DOWELL, F.E.; KOFOID, K.D. Genetic analysis of feed quality and seed weight of sorghum inbred lines and hybrids using analytical methods and NIRS. Euphytica, v.127, p.31-40, 2002.

KAYS, S.E.; WINDHAM, W.R.; BARTON, F.E. Prediction of total dietary fiber in cereal products using near-infrared reflectance spectroscopy. Journal of Agricultural and Food Chemistry, v.44, p.2266-2271, 1996.

LEE, S.C.; PROSKY, L. International survey on dietary fiber: definition, analysis, and reference materials. Journal of Association of Official Analytical Chemists International, v.78, p.22-36, 1995.

MANTHEY, F.A.; HARELAND, G.A.; HUSEBY, D.J. Soluble and insoluble dietary fiber content and composition in oat. Cereal Chemistry, v.76, p.417-420, 1999.

PROSKY, L.; ASP, G.N.; SCHWEIZER, T.F.; Derives, J.W.; FURDA, I. Determination of insoluble and soluble dietary fiber in foods and food products: collaborative study. Journal of Association of Official Analytical Chemists International, v.75, p.360-367, 1992.

SILVA, l Composição química de trigo e de aveia e efeito dos teores e proporções de fibra alimentar sobre a resposta biológica de frangos de corte e ratos. 2002. 188p. Tese (Doutorado) Universidade Federal do Rio Grande de Sul, Porto Alegre.

TEDESCO, M.J.; VOLKWEISS, S.J.; BOHNEN, H. Análise de solo, planta e outros materiais. Porto Alegre: Departamento de Solos da UFRGS, 1985. Paginação irregular. (Boletim técnico, 5).

WHITE, P.J. Dietary fiber. In: MURPHY, C.F.; PETERSON, D.M. (Ed.). Designing crops for added value. Madison: American Society of Agronomy; Crop Science Society of America; Soil Science Society of America, 2000. p.201-214.

WU, J.G.; SHI, C.H. Prediction of grain weight, brown rice weight and amylose content in single rice grains using near-infrared reflectance spectroscopy. Field Crops Research, v.87, p.13-21, 2004.

Recebido em 20 de junho de 2005 e aprovado em 18 de janeiro de 2006 